\title{
Research on the Paths to Improve the Information Acquisition Ability of Students in Higher Vocational Colleges
}

\author{
Taohong Sun ${ }^{1,2}$, Jiayin Liu ${ }^{1}$ \\ ${ }^{1}$ Institute of Scientific and Technological Information, Nanjing University of Aeronautics and Astronautics, Nanjing, China \\ ${ }^{2}$ Anhui Automobile Industrial Technician Institute, Hefei, China \\ Email: 43963312@qq.com
}

How to cite this paper: Sun, T.H. and Liu, J.Y. (2021) Research on the Paths to Improve the Information Acquisition Ability of Students in Higher Vocational Colleges. Open Access Library Journal, 8: e8150. https://doi.org/10.4236/oalib.1108150

Received: November 4, 2021

Accepted: December 5, 2021

Published: December 8, 2021

Copyright (๑) 2021 by author(s) and Open Access Library Inc.

This work is licensed under the Creative Commons Attribution International License (CC BY 4.0).

http://creativecommons.org/licenses/by/4.0/

\section{(c) (i) Open Access}

\begin{abstract}
In the context of the era of mobile Internet boom and knowledge explosion, facing the increasingly competitive social environment, it is of great significance for the personal development of students in higher vocational colleges to study how to effectively apply various types of online information to improve their information literacy. In this paper, we clarify the connotation of information acquisition ability based on existing research and subdivide it into five dimensions: independent learning ability, innovative learning ability, continuous learning ability, teamwork ability and systematic thinking ability. On this basis, we explore five ways to improve the information acquisition ability of students in higher vocational colleges: improving their own independent learning ability, improving their own innovative learning ability, improving their own continuous learning ability, improving their own teamwork ability, and improving their own systematic thinking ability.
\end{abstract}

\section{Subject Areas}

Library and Information Science

\section{Keywords}

Higher Vocational Colleges Students, Information Acquisition Ability, Promotion Paths

\section{Introduction}

In the current era of knowledge explosion, everyone must have the ability of self-learning and lifelong learning, and for students in higher vocational colleges, 
the school years are precisely the key period for them to develop their learning habits and improve their learning ability. As the knowledge base and information literacy of students in higher vocational colleges vary greatly, their information acquisition ability is bound to be different. Therefore, it is necessary to clarify the information acquisition mechanism of students in higher vocational colleges so as to provide a more comprehensive and systematic solution for all students. In the era of mobile Internet boom and knowledge explosion, in the face of the increasingly competitive social environment, it is important to study how students in higher vocational colleges can effectively use various kinds of online information to improve their information literacy for their personal development. This study analyzed the connotation of the concept of information acquisition, systematically analyzed the components of information acquisition ability of students in higher vocational colleges, and on this basis explored the ways to promote their ability to improve information acquisition.

\section{The Connotation of Information Access}

In the early 1990s, most students typically needed to visit a research library and browse the stacks in order to find the source of the information they needed. Now, however, with just a smartphone or an Internet terminal, students can access all types of knowledge anywhere without entering the library. The complete disruption of the traditional medium of print resources also means that students must have highly information literacy, be able to locate multimedia resources, assess their qualities, extract the information they contain, meet their information needs and develop their own body of knowledge.

However, different scholars had different understandings and definitions of the connotation of information access. Some scholars regarded it as an essential quality, also called data literacy, while others believed that it should be a learning ability. Bohannon et al. considered information access literacy among college students as a series of abilities to encode specific information such as identifying information types, keyword searches, subject searches, identifying online libraries, distinguishing information sources, integrating information, evaluating information, compiling and absorbing [1]. Robison stated that information access for college students was a kind of information literacy, a comprehensive set of competencies that includes the reflective discovery of information, an understanding of how information is produced and valued, and the application of information in the creation of new knowledge [2]. Bartol et al. argued that information access for students included information needs identification, information access, information evaluation, and information use four specific learning skills and techniques [3]. According to Lyu [4], for college students, unlike the indoctrination learning and fixed deductive and logical reasoning ability in high school, college students in the ocean of information must have the skill of swimming, first of all, the skill of identifying different information sources in and out of school. The first was the skill of recognizing different information sources in and out of school, the second was the methodological skill of being 
familiar with the search language and search methods, and the second is the skill of skillfully using a comprehensive approach to knowledge acquisition, and these skills can be acquired and mastered through a hierarchical and phased methodological teaching and training mode in schools and classrooms.

Caminita directly suggested that access to information should be established as a course of study to develop information literacy and skills for students [5], and Shao further suggested that the development of students' information literacy and competencies was closely related to the work of not only lecturers but also school libraries [6], which help students to develop transferable skills, such as the use of online services to access the information they need. The libraries of modern universities should especially emphasize the use of modern information technology to collect relevant information in order to ensure easy and fast access to information, and provide regular training and lectures on information access, library literature retrieval, online course search, and other related skills to help students master and improve their information skills. This would help students to acquire and improve their information skills and to better explore the treasure of knowledge.

In summary, although there were two academic genres of information literacy in existing research, neither genre denied that information acquisition was an ability available, and it was for this reason that this study, was of practical significance.

\section{Composition of Information Acquisition Ability}

\subsection{Self-Directed Learning Ability}

The first thing to cultivate the information ability of students in higher vocational colleges was to build up the learning ability of acquiring network information independently. In order to establish the active consciousness of independent learning, we must first break the fixed mental model. Mental mode was an individual's view of things, which described how an individual finds out problems, analyzed them and solved them. Higher vocational colleges students' mental mode directly determined their information acquisition behavior. When students in higher vocational colleges were still immersed in the passive learning mode of classroom indoctrination, it was difficult for them to break the established learning mode to actively search for online information spontaneously and consciously [7]. However, the objective environment was ever-changing, and it was difficult to correct the deep-rooted and outdated concepts of the poor mental model. Therefore, for students in higher vocational colleges, they need to improve their mental models and make immediate corrections [8], so that they could actively acquire online information and learn online knowledge on their own [9].

\subsection{Innovative Learning Ability}

College students' ability to learn creatively directly determines their ability to 
access information [10]. This study focused on the innovative learning ability of students in higher vocational colleges to be able to solve practical problems using the Internet's network information. Such problem solving facilitates students to connect their own knowledge base with the Internet's ocean of knowledge and use the corresponding knowledge to inspire ideas and solve problems. Through this connected information search, on the one hand, students will more easily understand existing concepts and help them better understand the problem at hand, and on the other hand, it will facilitate students to look at the problem from other perspectives, from diverse perspectives, which in turn will help inspire the formation of more problem solutions. The development of such problem-solving information-seeking skills helps to maximize the information gain of students [11].

\subsection{Continuous Learning Capability}

In practical applications, it is often difficult to solve problems through one or several retrievals, so according to the information risk and processing model, students of higher vocational colleges need continuous information acquisition to improve information sufficiency and continuously improve the current problem solution. Fu S also pointed out that after obtaining positive feedback from information, information seekers will feel the value of their information search, and also in order to further obtain more valuable and effective information, they will continue to search for information [12]. For students of higher vocational colleges, their continuous learning behavior cannot be achieved without their self-monitoring and self-regulation. By regularly summarizing the learning situation, conducting evaluation and self-reflection, understanding the areas that need to be improved and making timely adjustments, this is conducive to developing good habits of good thinking and summarizing; adopting a questioning attitude towards a problem that is not understood or not clear, daring to question and question authority, and making progress from questioning; most importantly, strengthening time management, reasonably arranging spare time and classroom learning, strictly following the original The most important thing is to strengthen time management, arrange spare time and classroom learning reasonably, strictly follow the original plan, really happy learning, realize active learning, continuous learning [13].

\subsection{Team Work Ability}

In the age of information explosion, it is difficult to rely on only one person's knowledge for the solution of a particular problem. For students in higher vocational colleges, a class assignment or a topic solution often requires a discussion group to work together to acquire and organize information. A problem-oriented information acquisition team is conducive to stimulating mutual communication and encouraging each other to facilitate the acquisition of information. High level students can play a supportive role in the group, middle level students 
can be rewarded for their efforts, low level students can get help and encouragement from their high level peers, and at the same time, high level students are confident and motivated in being able to learn in the team, while for lower level students Their relationship with their peers reduces their social anxiety and increases the chances of imitating their peers [14].

\subsection{Systematic Thinking Skills}

Systems thinking is a holistic and dynamic way of thinking that analyzes and synthesizes the feedback and nonlinear characteristics of information seeking, which facilitates the information seeker to acquire information in a holistic and dynamic way rather than in a one-sided, static and intermittent way, thus constantly improving the current information seeking solution and constantly increasing the effectiveness and value of information acquisition [15]. From an early age, we are trained to break down problems into smaller problems and smaller parts to understand and solve them. This layered approach to thinking greatly increases the efficiency of problem solving [16].

Information access for students in higher vocational colleges is a comprehensive set of competencies that includes reflective discovery of information, an understanding of how information is produced and valued [2], and includes the key processes of categorization, sequential ordering, comparing and contrasting, summarizing, identifying problems, solving problems, and reflecting on problems. In terms of information acquisition, information categorization is the first step in establishing systematic thinking to grasp the value and validity of information through information categorization. Then, it is to rank the information according to its importance and grasp the focus of the ponderous information. Furthermore, through comparison and contrast, it is then necessary to screen the reliability and value of the information. The systematic thinking ability of information search also emphasizes the iterative thinking of the process of problem identification, problem analysis, and problem solving.

\section{Promotion Paths for Students in Higher Vocational Colleges}

\subsection{Improve Independent Learning Ability}

Through independent learning, it is beneficial for students to overcome obstacles. For the students of higher education institutions themselves, they must increase their understanding of society and not just confine themselves to their own small circle, which leads to nothing to do all day long and immerse themselves in the world of online games and entertainment variety shows due to the unknown of society. Contemporary college students should have high ambitions and know what they need to do in the future in order to know what they need to do, learn and reserve at the moment, so as to lay a solid foundation for the future. Only with learning goals will they not feel lost and do nothing, and they can take the initiative to learn, explore and search for the information and 
knowledge they really need.

The construction of the information platform enables students to learn independently and learn to apply the information platform under the guidance of teachers to obtain data and materials for daily learning. For example, through the information platform, students can not only obtain information resources related to textbooks, including exercises, teaching aids, typical cases, etc., but also start learning in well-known learning websites and educational websites at home and abroad through the Internet medium, and choose the knowledge points they are interested in to learn. By using the information platform, students can constantly improve and expand themselves, which not only breaks through the limitation of classroom teaching to students' learning, but also allows students to independently choose learning contents according to their own interests, effectively integrating traditional learning methods with online learning methods to further improve their knowledge and abilities.

\subsection{Improve Innovative Learning Ability}

The demand for complex and application-oriented talents emphasizes effective problem solving while highlighting the systematic nature of knowledge and the diversity of solutions. Therefore, improving students' independent innovation ability is an important foundation to meet this demand. This requires further expanding students' learning channels and broadening their knowledge. Interdisciplinary knowledge can effectively avoid preconceived subjective judgments in problem solving and enhance the objectivity and comprehensiveness of problem understanding. Through interdisciplinary education, students can break through the limitations of their existing knowledge and look at the world and problems from a more diverse perspective. In interdisciplinary education, it is necessary to further strengthen the articulation of knowledge in multiple subject areas based on expanding students' knowledge. Through teamwork or project-based teaching, students can apply their knowledge from various aspects of the curriculum to solve real-world problems, strengthen their ability to think for themselves about other fields of knowledge, form a memorable period of knowledge, and help students build a multidisciplinary knowledge framework that fits their own knowledge system.

Each professional course has several teaching and learning sessions, and integrating new media and technologies into each session of teaching can provide a new path for the cultivation of students' independent learning ability. Using computers, tablets, cell phones and other information terminals, we can use "micro-class", "catechism", "flipped classroom" and other Internet-mediated education methods to carry out teaching and learning. This allows students to learn online and offline simultaneously, extending the limited class time indefinitely and providing more space and time for students' learning.

\subsection{Improve Continuous Learning Ability}

The rapid iteration of knowledge implies the importance of continuous learning, 
which enhances the ability to continuously improve the ability to cope with increasingly complex real-world problems. In terms of the internal drivers of continuous learning, curiosity and the desire to challenge difficulties are internal forces for students to continue learning, so it is important to focus on discovering and cultivating students' curiosity about problem solving in lectures so as to strengthen their learning initiatives. In terms of the external influences on continuous learning, the learning environment, learning materials, and feedback on learning outcomes are the external drivers of students' continuous learning ability. Therefore, there is a need to focus on internal learning communication and experience sharing in the classroom during lectures, to strengthen talkable interaction, and to provide an environmental climate for continuous learning. Provide a good support of learning materials and learning platforms in or out of the classroom, such as relevant professional materials and online learning materials, to meet students' continuous and diversified needs for knowledge. The teacher needs to provide a clear feedback to the students' process and results, and this feedback will help the students to form a basic judgment about the knowledge learned in the course, and this judgment will help to provide experience or lessons for subsequent knowledge learning.

\subsection{Improve Teamwork Skills}

The development of students' teamwork skills can be understood at two levels. One level is to strengthen students' sense of teamwork. The previous education mode of university is basically based on individual assessment, and this assessment mode also forms students' self-led learning tendency, but the assessment mode of university and later is mostly based on both individual and team assessment mode, and university education is an important carrier of this mode change. Therefore, the training of university students should pay more attention to the cultivation of students' collective consciousness, so that students are not confined to their own small world. Another level of understanding is to cultivate students' ability to cooperate in a team, which is expressed in learning to find their own position in the team, how to identify problems and solve them as a whole, and how to manage conflicts in the team. The importance of this competency development is also highlighted by the fact that most students are largely inexperienced in teamwork during their secondary school years. Therefore, it is important to recognize the importance of group cooperation, to take the initiative to interact and communicate, to promote a reasonable collision of all kinds of ideas, and to strengthen the ability to work with different students and their sense of cooperation.

First of all, scientific grouping should be conducted to ensure the teaching effectiveness. When using cooperative learning mode for classroom teaching, students need to be grouped scientifically according to their depth of knowledge and ability to ensure that the number of students in each group is similar. Once the students are grouped, the teacher conducts classroom activities and guides the students to discuss and learn in small groups. The use of this teaching me- 
thod can effectively mobilize students' interest in learning, enliven the classroom learning atmosphere, and promote the orderly development of education.

\subsection{Improve Systematic Thinking Skills}

Criticality is considered to be an important factor in the successful development of college students' learning and one of the driving forces of the progress of society as a whole. Without thinking skills, students lack objective knowledge of their self-knowledge system, are more trapped in the prison of their self-cognitive system, and will not be able to break through their self-cognitive limitations. In addition, adequate learning of critical thinking skills during their college studies will enable them to effectively pursue their careers later in life when they enter the workforce. Critical thinking is a way of thinking that captures the essence, questions discernment, and is clear and agile, in which the thinker evaluates, synthesizes, and interprets relevant information related to the situation. This information must also be applied to solve a problem, decide on a course of action, find an answer to a given question or reach a reasonable conclusion.

Teachers can introduce exploratory questions according to the teaching content in the classroom, then discuss, exchange and dialogue around the questions raised, and pay attention to control the underlying ideas and implicit preconceptions that trigger knowledge, so as to provide students with space for dialectical thinking. And through the collision of different views, achieve the purpose of cultivating students' critical thinking skills.

\section{Conclusion}

This study systematically summarizes the components of information acquisition ability of students in higher education institutions into independent learning ability, innovative learning ability, continuous learning ability, teamwork ability, and systematic thinking ability, and proposes ways to help them improve their information acquisition ability. For higher education institutions, clarifying the mechanism and mechanism of online information acquisition for students in higher education institutions is conducive to schools to better carry out teaching and learning, and better play the role of a leader in teaching and education, so as to help students grow better. Through the understanding of the barriers of network information, corresponding courses and corresponding counseling are offered to help students in higher education institutions to better break the barriers on the way of learning, so as to realize the independent discovery, independent analysis and self-acquisition of the network information they need and promote the improvement of students' learning ability, thus helping them to realize their all-round development and provide solid knowledge guarantee for their future career and social life, and also promote the students' life and social values in their positions are also promoted.

\section{Conflicts of Interest}

The authors declare no conflicts of interest. 


\section{References}

[1] Bohannon, J.L., Arnett, E.J. and Greer, E. (2017) Learning Information Literacy Across the Curriculum (LILAC) and Its Impacts on Student Digital Literacies and Learning across the Humanities. 2017 IEEE International Professional Communication Conference (ProComm), Madison, 23-26 July 2017, 1-8. https://doi.org/10.1109/IPCC.2017.8013935

[2] Robison, M. (2017) Connecting Information Literacy Instruction with Transfer Student Success. Reference Services Review, 5, 511-526.

https://doi.org/10.1108/RSR-10-2016-0065

[3] Bartol, T., Dolnicar, D., Podgornik, B.B., Rodi, B. and Zoranovi, T. (2018) A Comparative Study of Information Literacy Skill Performance of Students in Agricultural Sciences. The Journal of Academic Librarianship, 3, 374-382. https://doi.org/10.1016/j.acalib.2018.03.004

[4] Lyu, J. (2003) A Theoretical and Practical Study of Information Acquisition Skills Training for College Students. Information Studies. Theory \& Application, 6, 543-546.

[5] Caminita, C.M. (2015) Embedding the Agriculture Librarian in an Agriculture Residential College: A Case Study. Journal of Agricultural \& Food Information, 16, 31-42. https://doi.org/10.1080/10496505.2014.984039

[6] Shao, X. and Purpur, G. (2016) Effects of Information Literacy Skills on Student Writing and Course Performance. The Journal of Academic Librarianship, 42, 670-678. https://doi.org/10.1016/j.acalib.2016.08.006

[7] Tan, J., Yang, M., Yang, Q. and Pan, W. (2016) A Study of Digital Science and Technology Museum User Demand Acquisition Based on Youth Mental Model. Art Technology, 6, 64-65.

[8] Han, Z., Cui, B. and Wang, F. (2018) An Experimental Study of Cognitive Evolution in Novice Users' Interaction with Bibliographic Databases: A Mental Model Perspective. Document, Information \& Knowledge, 4, 69-80.

[9] Zeng, X. (2018) Learning Characteristics and Teaching Method Innovation in University Classroom under Mobile Internet Environment. Journal of Hengyang Normal College, 6, 159-162.

[10] Baregheh, A., Rowley, J. and Sambrook, S. (2009) Towards a Multidisciplinary Definition of Innovation. Management Decision, 47, 1323-1339. https://doi.org/10.1108/00251740910984578

[11] Zhao, Y. (2018) Construction of a Digital Library Innovation and Learning Support Platform Based on Big Data and the Internet. Journal of Agricultural Library and Information, 10, 97-100.

[12] Fu, S., Chen, X. and Deng, S. (2017) A Study on the Transformation of User Information Behavior in Social Q\&A Communities-A Theoretical Model Construction from Information Adoption to Persistent Information Seeking. Document, Information \& Knowledge, 4, 80-88.

[13] Chen, S., Liu, W., Zhang, Y. and Xu, J. (2017) A Study of Group Differences in Self-Involvement in Information-Seeking Behavior-An Example of Online Learning for University Users. Information Science, 8, 129-133.

[14] Zhang, S.T. and Ruan, J.H. (2016) Exploring College Students' Information Behaviors and Influencing Factors-An Example of College Students' Mathematical Modeling Team. Library and Information Service, 4, 107-114.

[15] Zhou, C. and Han, Y. (2015) An Empirical Investigation of Collaborative Information Seeking and Retrieval Behavior of Academic Teams in Higher Education. In- 
formation Studies: Theory \& Application, 10, 110-115.

[16] Magnus, et al. (2015) The Diversity of Systemic Innovation Thinking. IMP Journal, 34, 241-253. 